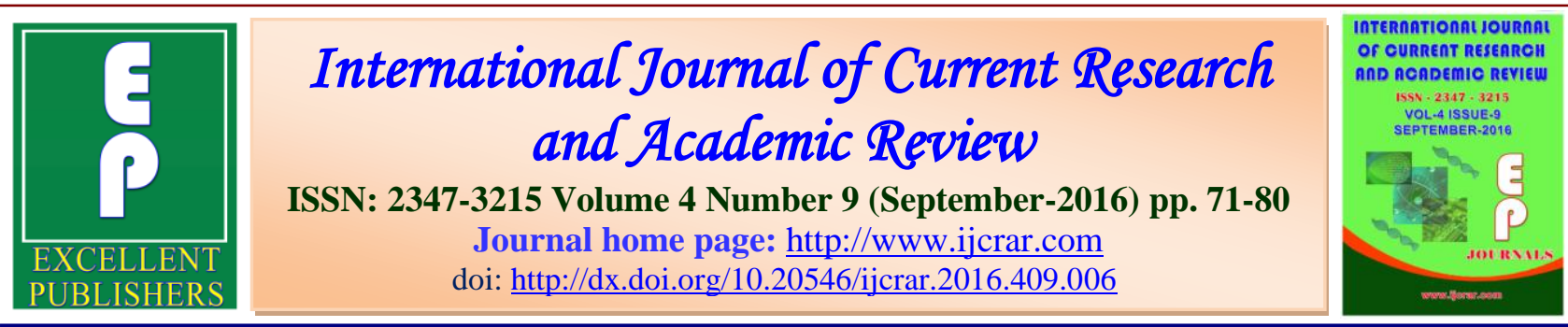

\title{
A Novel Study for Chemical Composition of Al-Ahdaab Field Crude Oil
}

\section{Mohsin O. Mohammed ${ }^{1}$, Tariq Abdul-Jaleel ${ }^{2}$, Aws Mseer Najres ${ }^{1}$ and Ibrahim H. Farhan ${ }^{1}$}

${ }^{1}$ Department of Chemistry, Faculty of Science, Kirkuk University, Iraq

${ }^{2}$ Department of Chemistry, Faculty of Science, Anbar University, Iraq

\section{*Corresponding author}

\begin{tabular}{|c|c|}
\hline KEYWORDS & A B S T R A C $\mathbf{T}$ \\
\hline $\begin{array}{l}\text { Crude oil } \\
\text { Fractionation } \\
\text { Chemical } \\
\text { composition } \\
\text { Al-ahdaab. }\end{array}$ & $\begin{array}{l}\text { This research included determination of chemical composition of al-ahdaab } \\
\text { crude oil (kute- Iraq) using liquid - solid chromatography method. The } \\
\text { current study involved separation the components of crude oil by column } \\
\text { chromatography was packing with alumina }\left(\mathrm{AL}_{2} \mathrm{O}_{3}\right) \text { as a stationary-phases } \\
\text { and several solvent as a mobile phase. The results of crude oil fractionations } \\
\text { were } 17.01 \% \text { Asphaltene, } 82.99 \% \text { Maltene, which separated to Paraffinic } \\
\text { (saturated) } 44.11 \% \text {, Aromatic } 30.11 \% \text { and Resin } 4.20 \% \text {. Crude oil } \\
\text { fractionations were characterized using Nuclear Magnetic Resonance }{ }^{1} \mathrm{HNMR} \\
\text { and Fourier Transform Infrared Spectrometer FT-IR to determine the } \\
\text { chemical composition of each part, which is that represents the first study and } \\
\text { novel results. This study also clarified the paraffinic compounds are the main } \\
\text { part of materials in the crude oil composition. }\end{array}$ \\
\hline
\end{tabular}

\section{Introduction}

Iraqi oil considers as one of the foremost discovered in the Middle East region. Baba Kurkur Field in Iraq is still more manufacturing than the other oilfield although its old age where it has discovered in 1927. Moreover, AL-Ahdeb field is one of the recently discovered oilfield, and it still in its tentative product stage. This oilfield locates in the middle of Iraq (kute governorate). Crude oil or petroleum is naturally occurring mixture that occur in the earth in liquid form (Mustafa et al., 2011; Mahinpey et al., 2010; Mamdouh et al., 2012), consisting predominantly of hydrocarbons with other element such as sulphur, nitrogen, oxygen, etc. appearing in the form of organic compounds which is in some cases form complexes with metals. Elemental analysis of crude oil shows that it contains mainly carbon and hydrogen in the approximate ratio of six to one weight (Bouhadda et al., 2007). Crude oil is a complex mixture and has different components of hydrocarbon groups as colloidal systems having a disperse phase composed of asphaltenes and resins. The precipitation of asphaltenes depends on the colloidal stability of these complex systems. 
Among the different factors that influence the stability of crude oils. In general, the presence of similar percentages weight of saturates, aromatics, and asphaltenes are considered signs of similar asphaltenes stability. Crude oil is easily transportable source of energy, concentrated and flexible from of fuel. At the beginning of the $20^{\text {th }}$ century the industrial revolution had progressed to the extent that the oil industry became the major supplier of the energy, because of the arrival of automobile. The oil achieved a primary importance as an energy source on which the world economy depends (Enekwe et al., 2013). To understand the physical properties and chemical composition behaviour of such complex mixtures, it is necessary to characterize the chemical structure of these mixtures. The chemical composition of a crude oil is classified according to its SARA content (saturates, aromatics, resins, and asphaltenes). Generally, these groups each with individual sub groupings, different components consisting of mainly hydrocarbons and some trace metals. Crude oils vary widely in their physical and chemical properties. They may be straws colored, green, brown or black, the last three being the most common colors (May- Elena et al., 2003; Joseph et al., 1997). The chemical composition importance of determining the optimization processes of referring, elicitation, and industrials of petroleum products because it represents in clear image the physical and chemical properties of oil which especially use to design the system of oil refinery and production (Mustafa et al., 2011; Mahinpey et al., 2010; Mamdouh et al., 2012). Molecular types in crude oils range from nonpolar, nonaromatic hydrocarbons to highly aromatic hydrocarbons, the molecular structures of which contain varying amounts of certain so-called heteroatoms, predominantly oxygen, nitrogen, and sulfur, together with parts-per-million amounts of metals because the number of molecules in crude oils with different chemical structures is extremely large, determination of crude oil composition by separation into its molecular components (Bouhadda et al., 2007). There are many reports on researches about the chemical composition of crude oils that have been reported to hydrocarbon contain (Carmen et al., 2000; Odebunmi et al., 2000; Ren Wenpo et al., 2006). The objective of this study is to elucidate the chemical composition of each fractionated for crude oils from AL-Ahdeb field using liquid- solid chromatography, and ${ }^{1} \mathrm{HNMR}$, FT-IR spectroscopy are used to characterize of functional groups.

\section{Experimental}

Raw Materials: Crude oil sample from ALAhdeb field (kute - governorate) was used in this study. The obtained crude stored in sealed glass ampoules in the dark, in air. The physiochemical properties of crude oil sample were determined such as: API gravity $=25.21$, Total Acid Number mg $\mathrm{KOH} / \mathrm{g}$ Sample $=0.11$ and Total Base Number mg KOH/g Sample $=<0.05$.

Chemical and reagent: The chemically pure grade $n$-Pentane, $n$-Heptane, Toluene, Methanol, Benzene and $n$-Hexane were used as the solvent of precipitant and fractionation, for all samples were purchased from sigma- Aldrich Co. Alumina and $\mathrm{CCL}_{4}$ from Fluka Co.

\section{Instrumentation and Measurements}

Methodology: Several experimental were carried out to fractionation of Crude oil to the main parts using Column Chromatography and common methods of Separation - Chromatography. All work reported was performed with standard laboratory equipment. 
${ }^{1}$ H-NMR Spectra: ${ }^{1}$ H-NMR spectra were recorded at $500.13 \mathrm{MHz}$ for protons on a Bruker $500 \mathrm{MHz}$ Avance 111, spectrometer operating at room temperature. The sample solutions were prepared in chloroform-d $\left(\mathrm{CDCl}_{3}\right)$ and tetramethylsilane (TMS) was added to the sample as an internal reference.

FT-IR Spectra: Fourier-transformed infrared spectroscopy sodium chloride $(\mathrm{NaCl})$ polish discs $(25 \times 2 \mathrm{~mm})$ were used to analyse oil samples under (FTIR) spectrometry. Background spectra were obtained by scanning two clean discs simultaneously in the instrument. One drop of used oil was placed between of two $\mathrm{NaCl}$ disc was placed in a Perkin-Elmer Spectrum -100 FTIR instrument and solid materials in the form of $\mathrm{KBr}$ discs four scans were carried out in the $4000-400 \mathrm{~cm}^{-1}$ range.

\section{Fractionation and Separation of Crude oil}

\section{SARA Separation}

Many attempts have been made to separate crude oils into groups or classes of compounds. The SARA-separation is an example of such group type analysis, separating the crude oils in four main chemical classes based on differences in solubility and polarity. The four SARAfractions are the saturates $(\mathrm{S})$, aromatics $(\mathrm{A})$, resins (R), and the asphaltenes (A). The SARA based on removal of asphaltenes by precipitation with a paraffinic solvent such as n-pentane or $n$-heptane before the chromatographic separation of the remaining crude oil on alumina (Trejo et al., 2007).

De-asphalting: The Separation of asphaltenes was carried out by two steps Firstly: removal of the insoluble materials in crude sample. In a $500 \mathrm{~mL}$ flask $10 \mathrm{~g}$ of crude sample and $40 \mathrm{~mL}$ of $\mathrm{CCL}_{4}$ was added. Mixture was shacked for 30 minutes, then filtrated to product insoluble materials. Secondly: In a $500 \mathrm{~mL}$ flask soluble of crude oil sample, normal hexane was added, mixture was shacked at room temperature for 1.5 hour to ensure the full solubility of Crude sample, Asphaltene precipitation occurs when an excess of $n$ pentane is added to mixture, then filtrated through the use of ashless paper No (42) mm by a Buchner funnel, the precipitate was washed until less for the color drops ensure complete. Asphaltene was separated in the precipitate part and soluble are Maltenes part.

\section{Liquid- solid chromatography separation of Crude Oil}

\section{Fractionation of Maltenes by Column Chromatography}

The soluble part (maltenes) was evaporated at room temperature to get a dry maltenes and several stationary phases were used for laboratory fractionation column by using $n$ hexane, SARA method enables the separation of maltenes into groups (Saturated, Aromatic, Resin and Asphaltene) This method is an extension of column liquid -solid chromatography to get more precise separation, packed columns are employed packed under vibration. ASTM (D3279).

\section{General Procedure}

A glass column $(100 \times 2 \mathrm{~cm})$ was used for the present work. Column Chromatography packed (mobilizes) under vibration in the activated stationary phase (alumina), was activated at $350{ }^{\circ} \mathrm{C}$ for $2 \mathrm{hrs}$. Maltenes part of $8 \mathrm{~g}$ was dissolved with a small amount of $n$-heptane then transferred to the chromatography column. First part of a saturated hydrocarbon was fractionated by using $n$-heptane as solvent. Second part of 
aromatic was separated by using toluene. Third part of resin separated using methanol, once fractionation processes finished of the three parts with change colors. The three fractions were collected and the solvents were removed from them by distillation. Samples were further dried under vacuum to measure their weights to estimate the kinds of each fraction part. The speed of the coming down drops was an (5) drops rate per minute in all fractionation process at the chromatography column as shows in Scheme.1

Fractionation by alumina $\left(\mathrm{Al}_{2} \mathbf{O}_{3}\right):$ A $50 \mathrm{~g}$ of alumina $(80-100 \mu \mathrm{m})$ where activated at $350{ }^{\circ} \mathrm{C}$ for 3 hrs then mixed with a small amount of $n$-heptane (emulsion) to ease transfer to the column to get a good packing without gaps and bubbles. Maltenes part $8 \mathrm{~g}$ was dissolved with $n$-heptane, Paraffin compound (saturated) part was coming down with pale yellow colures. Fractionation side red when the coming down drops which received of eluent (heptane) becomes colorless, then toluene had been added to fractionate aromatic part which has orange colors. Fractionation of the last part (Resin) which high polarity was complete carried out by methanol. The product was of orange- red color. The fractionation when the eluent drops become colorless. Three samples were collected and then distilled, dried and evaporated for measuring the weights of fractions and determined the kinds of every fractionated part of petroleum crude.

\section{Result and Discussion}

There are many parameters that is operational in the separation of crude oil constituents such as (polarity, aromaticity, molecular weight, solvent power, time required to allow the precipitating/ extracting, temperature, pressure, ratio of the precipitating/extracting). SARA separation is convenient and inexpensive and has been utilized extensively in the oil industry. Crude oils from AL-Ahdeb field exhibit a wide range of physical and chemical properties and the SARA-separation can be seen to give information somewhat between that obtained by elemental analysis and analysis for individual molecules. The chemical composition of crude oils will in the following to be discussed on the SARAfractions. Table. 1 shows a summary of the main characteristics of the studied crude oils (Elham et al., 2013).

\section{Quantitative analysis of the ${ }^{1}$ HNMR}

Proton Nuclear Magnetic Resonance ${ }^{1}$ HNMR Spectroscopy has been applied to petroleum chemistry to provide details information of the hydrocarbon chemistry of raw petroleum and its various products (Ren Wenpo et al., 2006). ${ }^{1}$ HNMR can be a useful tool due to investigation of distribution hydrogen type and molecular mobility it was found the type of $\mathrm{H} \%$ in Crude sample at Table 2. Study was achieved by using the area under the curve and by identifying the absorption of protons. Which include aromatic hydrogen $\mathrm{H}_{\mathrm{a}}$ at chemical shift with rang between 6.5 - 8.5 ppm. naphthenic hydrogen $\mathrm{H}_{n}$ at rang 1.42.2 ppm. Methylene hydrogen $\mathrm{H}_{\mathrm{my}}$ of paraffin compound at rang 0.9 $-1.8 \mathrm{ppm}$, methyl hydrogen $\mathrm{H}_{\mathrm{me}}$ at ring $0.5-1.4 \mathrm{ppm}$, hydrogen of alpha aromatic ring $\mathrm{H} \alpha$ at 1.7 $3.4 \mathrm{ppm}$. Through Information from the values of the ${ }^{1}$ HNMR results obtained the methylene hydrogen of paraffin compound $\mathrm{Hmy} \%$ are a higher percentage in asphaltene part of AL-Ahdeb crude oil. The different types of hydrogen atoms are given in Table 2 (Ahammed et al., 2011). From this figure 1 , one could observe that asphalten contains a high proportion of methylene groups. Followed by methyl groups, and that the 
ratio of naphthenic protons to the alpha aromatic are close together in the relative distribution (Akmza et al., 2011). The fractionated parts of maltenes (paraffinic, aromatic, resin) which separated with column chromatography, by using alumina a stationary phase The ${ }^{1}$ HNMR profile of maltenes fractionation part have been provided in table 3 and fig 2-4. AL-Ahdeb crude oil fractions using FTIR transmission spectra (inverses of absorbance spectra) which showed absorption of asphaltene band
( $\mathrm{KBr}$ disc) $\mathrm{cm}^{-1}$ from figures.5. Absorbance peaks of the following functional groups: aliphatic $\mathrm{CH}_{2}$ and $\mathrm{CH}_{3}$ stretch, aromatic $\mathrm{C}-\mathrm{C}$ ring-breathing stretch, methyl $\mathrm{CH}_{3}$ asymmetric and symmetric stretches, carbonyl and carboxyl stretch, pyrrolic $\mathrm{NH}$ stretch, and sulfoxide stretch. In addition, many of the spectra contain one of the following absorbance's: free $\mathrm{OH}$ stretch from 3424 to $3436 \mathrm{~cm}^{-1}$ indicate of phenolic and Alcohols $\mathrm{OH}$ stretch, and amidecarbonyl stretch.

Scheme.1 Illustration of SARA test

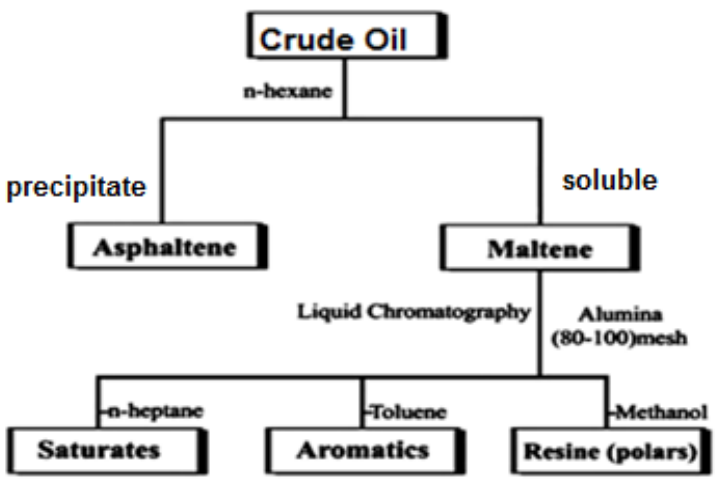

Table.1 Wt. \% of fractionation part come from SARA test

\begin{tabular}{|c|c|c|}
\hline Solvent & Expected of isolated materials & Alumina \\
\cline { 3 - 3 } & & Wt \% \\
\hline Heptane & Paraffinic & 44.11 \\
\hline Toluene & Aromatic & 30.11 \\
\hline Methanol & Resin & 4.20 \\
\hline Hexane & Asphaltene & 17.01 \\
\hline CCL $_{4}$ & Insoluble & 0,7 \\
\hline- & Residue & 2.9 \\
\hline
\end{tabular}

Table.2 Distribution of proton $\mathrm{H} \%$ by $1 \mathrm{HNMR}$ Spectroscopy of Asphaltene

\begin{tabular}{|c|c|c|c|c|c|}
\hline Hydrogen Type & $\mathbf{H}_{\mathrm{my}}$ & $\mathbf{H}_{\mathrm{me}}$ & $\mathbf{H}_{\mathrm{n}}$ & $\mathbf{H \alpha}$ & $\mathbf{H}_{\mathrm{a}}$ \\
\hline Asphaltene sample & $\mathbf{4 7 . 8 6}$ & $\mathbf{2 1 . 5 0}$ & $\mathbf{1 3 . 6 5}$ & $\mathbf{9 . 1 8}$ & $\mathbf{7 . 8 0}$ \\
\hline
\end{tabular}


Int.J.Curr.Res.Aca.Rev.2016; 4(9): 71-80

Table.3 Distribution of proton $\mathrm{H} \%$ by 1 HNMR Spectroscopy of maltenes fractionated

\begin{tabular}{|c|c|c|c|c|c|}
\hline Hydrogen Type & $\mathbf{H}_{\mathrm{my}}$ & $\mathbf{H}_{\mathrm{me}}$ & $\mathbf{H}_{\mathrm{n}}$ & $\mathbf{H \alpha}$ & $\mathbf{H}_{\mathrm{a}}$ \\
\hline paraffin sample & 46.54 & 34.33 & $\mathbf{8 . 1 2}$ & 4.53 & 4.65 \\
\hline Aromatic sample & 47.67 & 17.53 & $\mathbf{8 . 6 5}$ & 7.89 & 12.67 \\
\hline Resin sample & 34.23 & 15.65 & 10.54 & 7.42 & 10.61 \\
\hline
\end{tabular}

Fig.1 HNMR spectra of Asphaltene

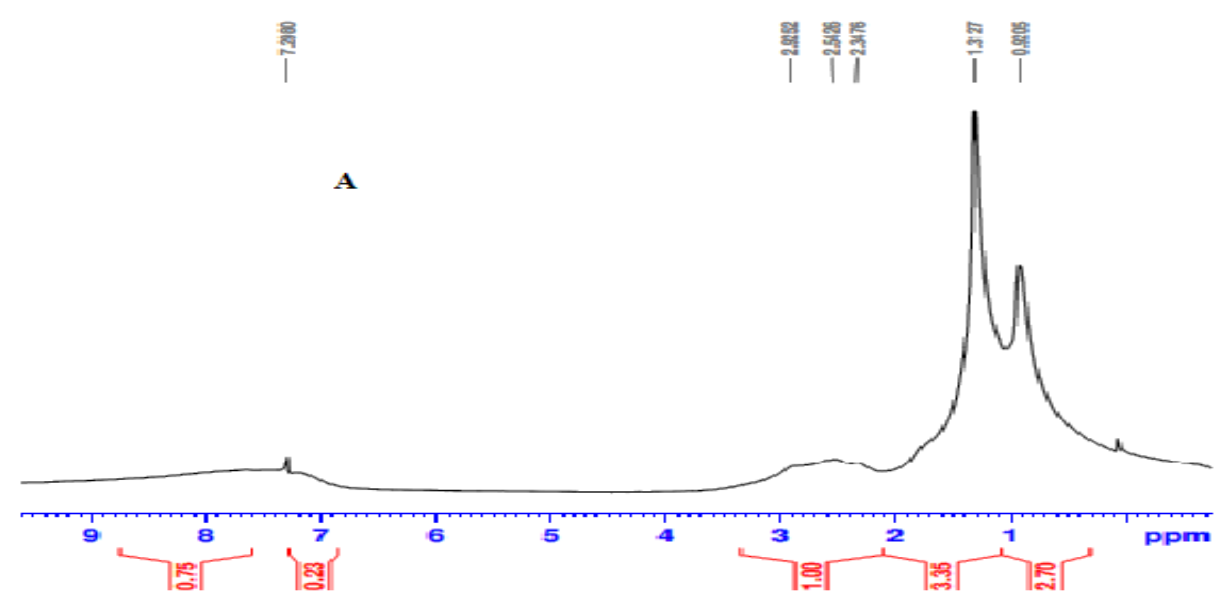

Fig.2 1HNMR spectra of paraffin
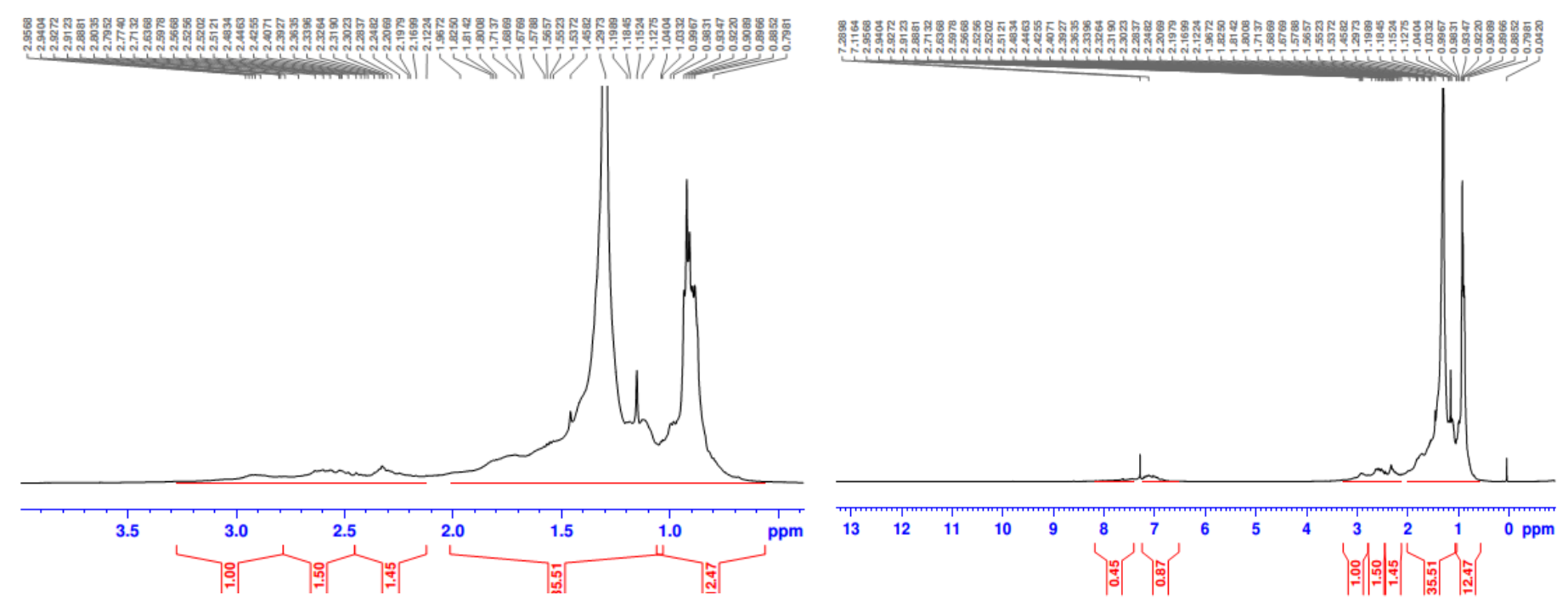
Int.J.Curr.Res.Aca.Rev.2016; 4(9): 71-80

Fig.3 1HNMR spectra of aromatic

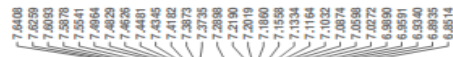

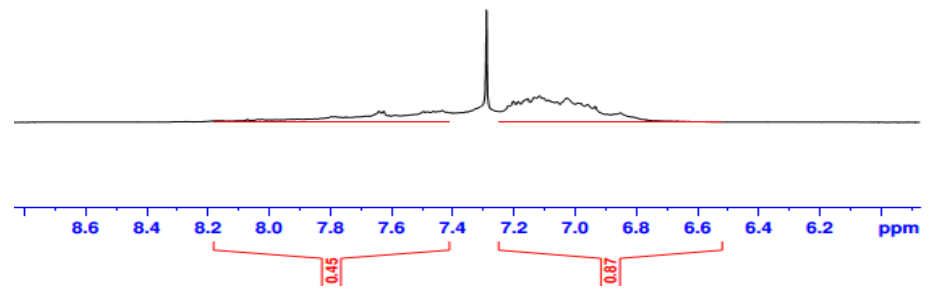

Fig.4 1HNMR spectra of resin
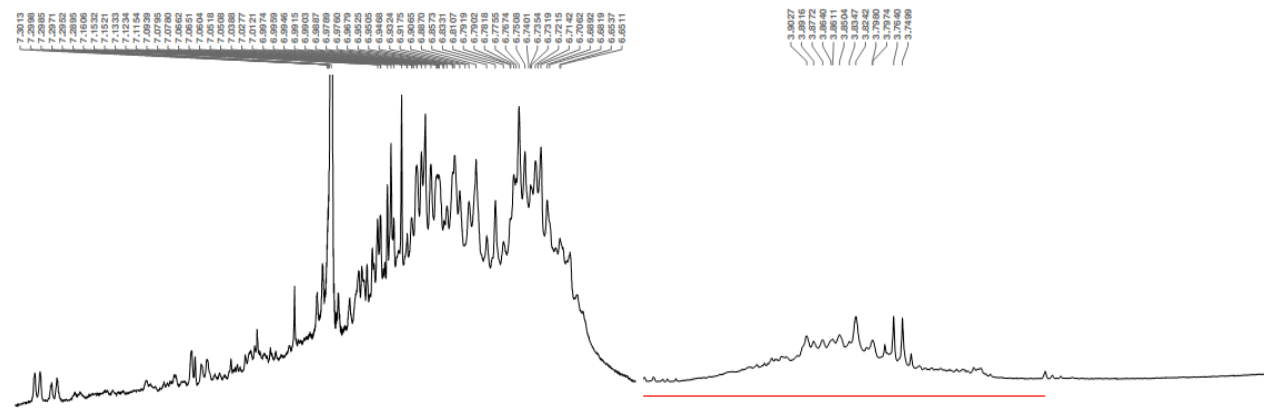

Fig.5 FTIR spectra for SARA extraction of AL-Ahdeb crude oil

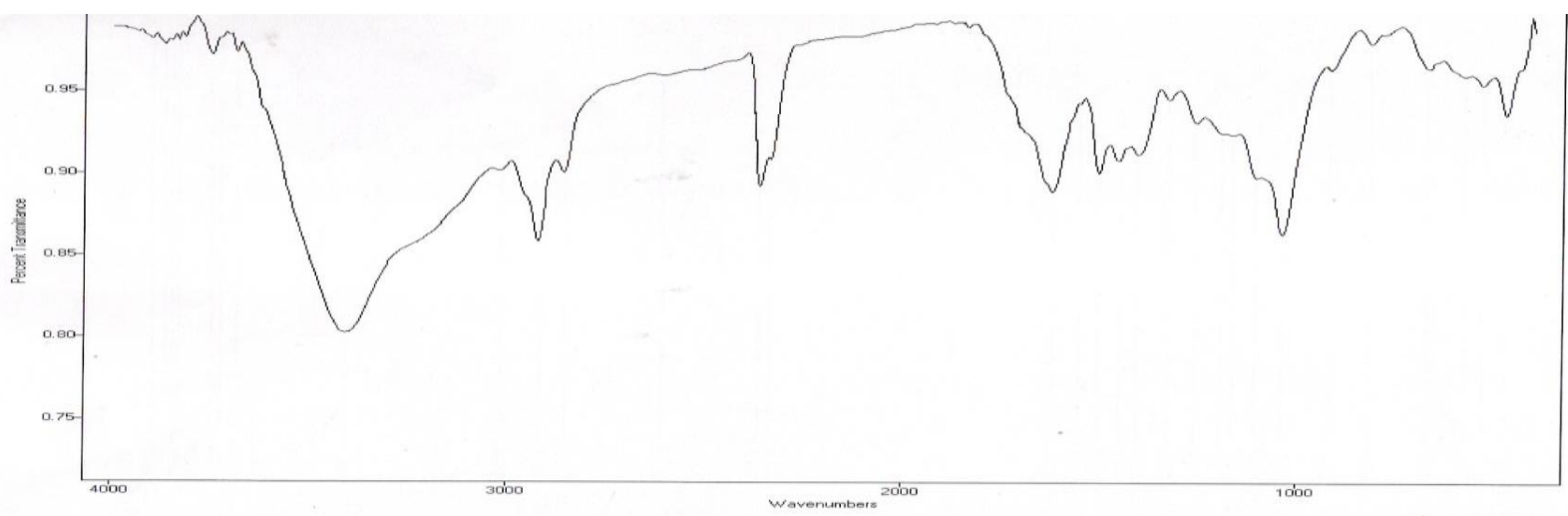



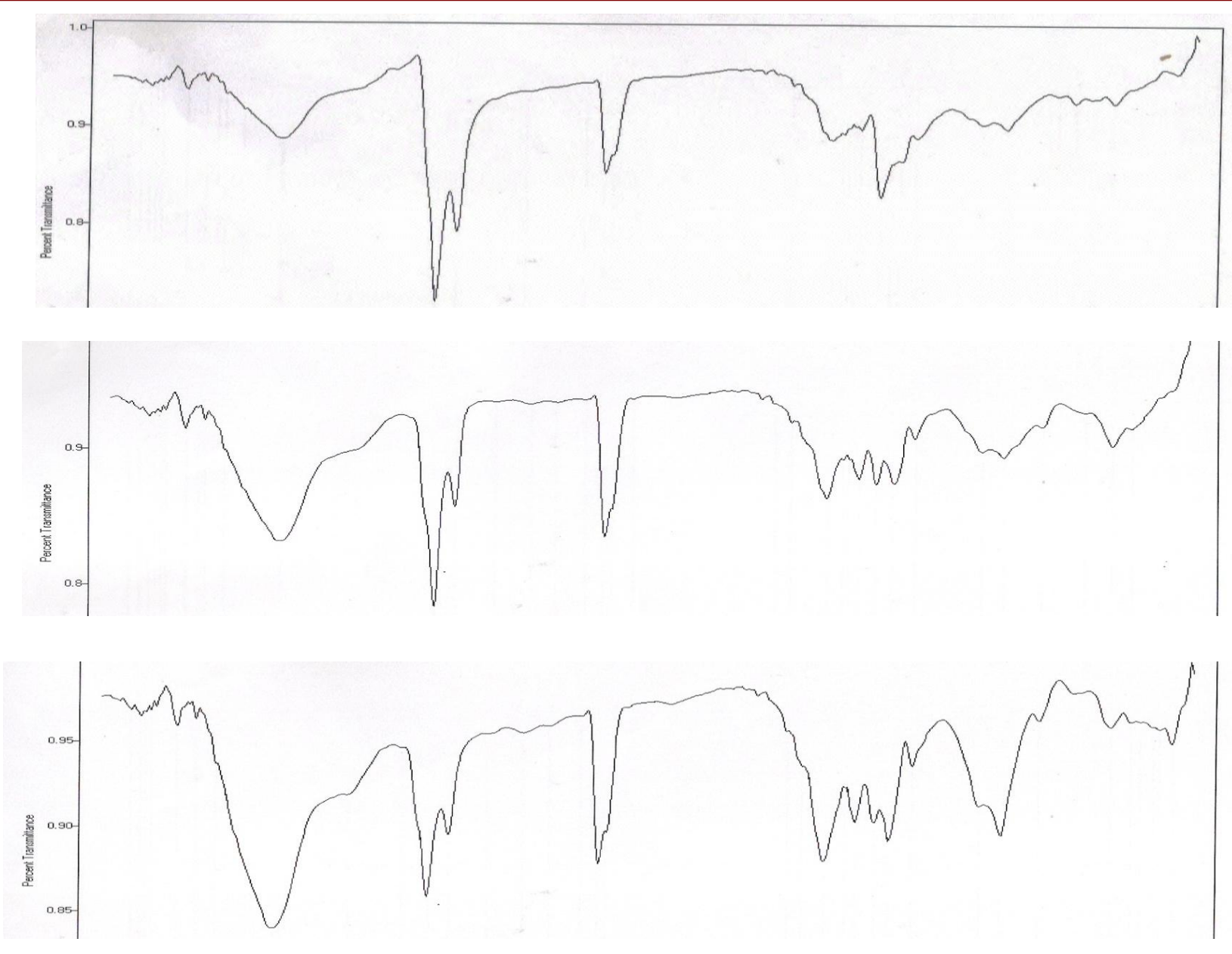

Each of these absorbance's has been carefully identified in the spectra large absorbance intensities for aliphatic $\mathrm{CH}_{2}$ and $\mathrm{CH}_{3}$ stretches in the wavelength range from 2800 to $3000 \mathrm{~cm}^{-1}$, significant absorbance for symmetric and asymmetric $\mathrm{CH}_{3}$ bending modes in the wavelength range from 1350 to $1500 \mathrm{~cm}$ and aromatic C-C ring-breathing stretches at a frequency of about 1600-1605 $\mathrm{cm}$, asymmetrical stretching vibration $\mathrm{CH}_{3}$ to 1411-to $1450 \mathrm{~cm}$, Sulfoxide $\left(\mathrm{C}_{2} \mathrm{~S}=\mathrm{O}-\right)$ from 1029 to $1032 \mathrm{~cm}$ and peak at $806 \mathrm{~cm}$ out-of-plane vibration of ring $\mathrm{C}-\mathrm{H}$. However, the paraffinic fractionated was confirmed by FTIR spectrum Figure.5. More detailed information of the chemical structure of paraffinic obtained by following the absorptions of $\mathrm{C}-\mathrm{H}$ stretching in the alkanes 3000 to $2840 \mathrm{~cm}^{-1}$. The band at
$2923 \mathrm{~cm}^{-1}$ indicates of vibration of $\mathrm{CH}_{2}$ methyl groups that at $2857 \mathrm{~cm}^{-1}$ attributed of $\mathrm{CH}_{3}$. The band located at $1623 \mathrm{~cm}^{-1}$ to amide stretching, vibrations for $\mathrm{C}-\mathrm{H}$ at 1515 $\mathrm{cm}^{-1}$ indicate the methylene $\left(-\mathrm{CH}_{2}-\right)$ chains, the band from 1461 to $1403 \mathrm{~cm}^{-1}$ stretching of $\mathrm{CH}_{3}$, band at 1110 to $1033 \mathrm{~cm}^{-1}$ for C-O bending and $674 \mathrm{~cm}^{-1}$ for $\mathrm{c}-\mathrm{c}$ vibration out of the plane (Fredericks et al., 1985). The aromatic $\mathrm{C}-\mathrm{H}$ stretching band, which occurs between 3100 and $3000 \mathrm{~cm}^{-1}$, did not appear on the spectra due to the weak $\mathrm{C}-\mathrm{H}$ stretch in aromatic compounds, band at $1407 \mathrm{~cm}^{-1}$ attributed to asymmetry bend of $\mathrm{CH}_{3}$, the band at $1330 \mathrm{~cm}^{-1}$ is indicative of $\mathrm{H}-\mathrm{C}=\mathrm{C}$ groups and a new band appeared at $1037 \mathrm{~cm}^{-}$ ${ }^{1}$ which are related to the $\mathrm{C}-\mathrm{C}$ aromatic, since low boiling aromatics are depleted relative to saturated compounds. The resin 
fractionated is the oil component and has polar aromatic compounds. The absorption band located at $1508 \mathrm{~cm}^{-1}$ Indicate the presence of $\mathrm{C}-\mathrm{H}$ aromatic, bands related to $-\mathrm{CH}_{2} \mathrm{CH}_{3}$ vibrations appear in the 1454 $\mathrm{cm}^{-1}$, observed band at $1261 \mathrm{~cm}^{-1}$ was $-\mathrm{CH}_{2}$ $\mathrm{CH}_{2}$-vibration, the band occurred at 917 and $817 \mathrm{~cm}^{-1}$ are representing hydrocarbons C-C in the aromatic ring or polyaromatic polar compound and observed band in the 671 and $558 \mathrm{~cm}^{-1}$ attributed to $\mathrm{C}-\mathrm{X}$ aliphatic halogen compound (Silverstein, 1991). Combining structural analysis results obtained from elemental analysis, FTIR and ${ }^{1}$ HNMR of fractions, the possible hypothetical molecular structure for asphaltene, paraffinic, aromatic and resin are represented as in Figures 1-5 which were successfully method for determination of crude oil component.

\section{Conclusions}

In this study several important structural parameters are proposed and calculated through the analysis of quantitative ${ }^{1} \mathrm{HNMR}$ and FTIR spectra, including the number of alkyl chain substituents to aromatic rings of crude oil, which has been used for characterization and determination of diverse compositions of AL-Ahdeb crude oil which were separated into compounds classes via SARA technique to four fractionated of different structures. The high content of paraffinic and low resin supported that AL-Ahdeb crude was medium crude oil. Hypothetical structures for four fractions were proposed paraffinic structure was contained long aliphatic compounds. The aromatic fraction consisted of aromatic ring with branched paraffin's, the resin part was composed of fused polar aromatic groups with branch paraffin. Asphaltene was the most complex compositions. However, the present study was a novel and has provided insight in to the chemical structure of ALAhdeb crude oil.

\section{Acknowledgments}

MOM wishes to thank the Ministry of Higher Education and Scientific Research, Iraq for the award of the grant.

\section{References}

Ahammed, M.A., Tighe, S. 2011. Asphalt pavements surface texture and National Research, Council, Ottawa, in press, Volume 39 1-9.

Akmza, S., Iscan, O., Gurkaynak, M.A., Yasar, M. 2011. The Structural Characterization of Saturate, Aromatic, Resin, and Asphaltene Fractions of Batiraman Crude Oil, Petroleum Sci. Technol., 29: 160-171.

Mamdouh, T., Ghannama, Basim AbuJdayil. 2012. Rheological properties of heavy \& light crude oil mixtures for improving flow ability, J. Petroleum Sci. Engi., 81: 122-128.

Bouhadda, Y., Bormann, D., Sheu, E., et al. 2007. Characterization of Algerian Hassi-Messaoud asphaltene structure using Raman spectrometry and X-ray diffraction, J. Fuel, 86: 1855-1864.

Carmen Garcia el, M., Carbognani, L., Orea, M., Urbina A. 2000. The Influence of Alkane Class-Type on Crude Oil Wax Crystallization and Inhibitors Efficiency J. Petroleum Sci. Engi., Vol.25, No.3-4, pp.99-105, ISSN 0920-4105.

Elham Keshmirizadeh, Somayeh Shobeirian, Mahmoud Memariani. 2013. Determination of Saturates, Aromatics, Resins and Asphaltenes (SARA) Fractions in Iran Crude oil Sampl, Study of the Geochemical Parameters, J. Appl. Chem. Res., 7(4): 15-24. 
Enekwe, Chukwudi Benedict, Okoro, Hyceinth Akpa. 2013. Analytical studies of poor performance of research, Volume 3, Issue 3.

Fredericks, P.M., J.B. Lee, P.R. Osborn and D.A. Swinkels. 1985. Materials characterization using factor analysis of FTIR spectra.Part2: mathematical and statistical consideration .Appl. Spectroscopy, V39, No.2, pp311-315.

Joseph, D., McLean and Peter, K. Kilpatrick. 1997. Comparison of Precipitation and Extrography in the Fractionation of Crude Oil Residua, Energy \& Fuels, 11: 570-585.

May- Elena Dominguez-Rosado and John Pichtel. 2003. Chemical characterization of fresh Weathered motor oil, Proceedings of the Indiana Acad. Sci., 112(2): 109-116.

Mahinpey, N., Murugan, P., Mani, T. 2010. Comparative kinetics and thermal behavior: the study of crude oils derived from Fosterton and Neilburg Fields of Saskatchewan, Energy Fuels, 24(3): 1640-1645.
Mustafa Versan Kok. 2011. Characterization of medium and heavy crude oils using thermal analysis techniques, Fuel Processing Technol., 92: 1026-1031.

Odebunmi, E.O., Ogunsatin, E.A. 2000. Characterization of crude oil and petroleum products elution liquid chromatographic separation. Bull. Chem. Soc. Ethiop., 6(2): 115-132.

Ren Wenpo, Shan Honghong, Yang Chaohe. 2006. Characterization of Average Molecular Structure of Heavy Oil Fractions. China Petroleum Processing and Petrochem. Technol. Ren Wenpo Yang, Vol. 13, No. 3, pp 1-7.

Silverstein, R.M., G.C. Bassler, and T.S. Morile. $\quad 1991 . \quad$ Spectrometric Identification of Organic Compounds,' John Wiley and Sons Inc, New York, N.Y.

Trejo, F., Ancheyta, J., Morgan, T.J., et al. 2007. Characterization of asphaltenes from hydrotreated products by SEC, LDMS MALDI, NMR, and XRD, $J$. Energy \& Fuels, 21(4): 2128-2121.

\section{How to cite this article:}

Mohsin O. Mohammed, Tariq Abdul-Jaleel, Aws Mseer Najres and Ibrahim H. Farhan. 2016. A Novl Study for Chemical Composition of Al-Ahdaab Field Crude Oil. Int.J.Curr.Res.Aca.Rev.4(9): 71-80. doi: http://dx.doi.org/10.20546/ijcrar.2016.409.006 